\title{
Etnohistoria y elaboración literaria en El Ayla, de José María Arguedas
}

Ethnohistoire et élaboration littéraire dans El Ayla, de José María Arguedas Ethnohistory and literary elaboration in El Ayla from José María Arguedas

\section{Edmer Calero del Mar}

\section{OpenEdition}

Journals

\section{Edición electrónica}

URL: http://journals.openedition.org/bifea/4793

DOI: $10.4000 /$ bifea.4793

ISSN: 2076-5827

\section{Editor}

Institut Français d'Études Andines

Edición impresa

Fecha de publicación: 1 abril 2006

Paginación: 75-86

ISSN: 0303-7495

Referencia electrónica

Edmer Calero del Mar, « Etnohistoria y elaboración literaria en El Ayla, de José María Arguedas », Bulletin de l'Institut français d'études andines [En línea], 35 (1) | 2006, Publicado el 08 abril 2006, consultado el 02 diciembre 2020. URL : http://journals.openedition.org/bifea/4793 ; DOI : https:// doi.org/10.4000/bifea.4793

\section{(@) $(\mathcal{Q} \Theta \Theta$}

Les contenus du Bulletin de l'Institut français d'études andines sont mis à disposition selon les termes de la licence Creative Commons Attribution - Pas d'Utilisation Commerciale - Pas de Modification 4.0 International. 


\title{
Etnohistoria y elaboración literaria en El Ayla, de José María Arguedas
}

\author{
Edmer Calero del Mar*
}

\begin{abstract}
Resumen
Se presenta un estudio del cuento El ayla a partir del lugar que la danza ayla ocupa en el trabajo etnológico arguediano. Arguedas nunca pudo demostrar el origen antiguo o prehispánico de esta danza. En el cuento El ayla, utilizando divinidades de la mitología de Huarochirí y elementos del carnaval andino, Arguedas da un ejemplo del método de «reconstrucción etnohistórica» que él propone para las danzas, años antes de la escritura de este cuento. El ayla, así construido, permite una lectura que obedece a las operaciones del pensamiento mítico.
\end{abstract}

Palabras clave - Arguedas, ayla, carnaval andino, cuento, limpieza de acueductos, mitología de Huarochirí, reconstrucción etnohistórica

\section{Ethnohistoire et élaboration littéraire dans El Ayla, de José María Arguedas}

\section{Résumé}

À partir de la place occupée par la danse ayla dans le travail ethnologique arguédien, l'auteur présente une étude sur le conte $E l$ ayla. Arguedas n'a jamais pu démontrer le caractère ancien ou préhispanique de cette danse. Dans le conte El ayla, utilisant des divinités de la mythologie de Huarochirí et des éléments du carnaval andin, Arguedas donne un exemple de la méthode de «reconstruction ethnohistorique » qu'il propose pour les danses, quelques années avant l'écriture de ce conte. El ayla, ainsi construit, permet une lecture qui obéit aux opérations de la pensée mythique.

Mots clés - Arguedas, ayla, carnaval andin, conte, nettoyage des canaux d'irrigation, mythologie de Huarochirí, reconstruction ethnohistorique 


\title{
Ethnohistory and literary elaboration in El Ayla from José María Arguedas
}

\begin{abstract}
The author proposes a study of the tale El ayla based on the place occupied by the ayla dance in Arguedian ethnological work. Arguedas was never able to demonostrate the ancient or prehispanic nature of this dance. A few years before writing El ayla, Arguedas gave an example of the method of ethnohistoric reconstruction that he proposes for the dances using the divinities of the Huarochiri myth and the elements of the Andean carnival The structure of El ayla when viewed in this way allows a reading that obeys the operation of mythical thought.
\end{abstract}

Key words - Arguedas, ayla, Andean carnival, tale, irrigation canal clean up, Huarochiri mythology, ethnohistoric reconstruction

Arguedas publica el cuento El ayla1 en 1967 (en Arguedas, 1983a: 235-239). En este cuento, los personajes indios de un pueblo serrano realizan las ceremonias de una fiesta ancestral ligada, como lo precisa Arguedas en el cuento, a la «limpieza de los acueductos». Después de los ritos ejecutados por los sacerdotes o Aukis y de la comida ceremonial de todos los participantes, tiene lugar la danza ayla. Terminada la danza, el cuento acaba cuando el niño blanco Santiago, espectador de estas festividades, se despide del pueblo.

En 1952 y en 1956, Arguedas hace trabajos de terreno en Puquio, en el departamento de Ayacucho y asiste, como etnólogo, a la fiesta de la limpieza de los acueductos que en ese lugar se Ilama Sequia2 ${ }^{2}$ de la que la danza ayla forma parte. El análisis y el estudio de esos testimonios los publica en su artículo Puquio, una cultura en proceso de cambio (Arguedas, 1956). En él constata que las letras de la danza ayla no son alusivas a la Sequia, siendo típica de ella (Arguedas, 1956: 222). A partir de esta fecha, esta danza no figura ni en la obra etnológica ni en la obra artística de Arguedas que hemos podido consultar. En 1967 reaparece en su obra ficcional en el conjunto de cuentos Amor Mundo: rápidamente mencionada en Don Antonio (1983b: 241), cuento del que no nos ocuparemos, y profusamente en el El ayla que analizaremos en este trabajo. A partir de este año reaparecerá también en sus escritos etnológicos (Arguedas, 1967; 1976b). Sabiendo que Arguedas no separa verdaderamente etnología y obra artística (Murra, 1987: 12), cabe preguntarse a qué corresponde esta reaparición de la danza ayla en sus publicaciones. ¿Arguedas encontró una fiesta o un rito al que podrían ser asociadas las letras de la danza ayla? El rastreo de la danza ayla en la obra etnológica de Arguedas muestra que a veces la considera danza con implicaciones erótico-religiosas, exclusiva de solteros y la asocia explícitamente a la danza huaylas y a los carnavales del Vilcanota. La determinación del origen del carnaval andino o poqoy, del que los carnavales del Vilcanota son una expresión, fue siempre una preocupación del etnólogo Arguedas. La búsqueda del origen de la danza huaylas, considerada danza de siembra y/o del carnaval andino, le lleva a Arguedas a la mitología de Huarochirí. Contrariamente a la danza ayla, descrita en sus trabajos etnológicos, la danza ayla que figura en el cuento contiene elementos tanto de uno de los carnavales del Vilcanota como de la mitología de Huarochirí. Esto parece indicar que, en El ayla, Arguedas le concede a la danza ayla una filiación carnavalesca y un antecedente histórico que no posee. Esta «reconstrucción histórica» enriquece la estructura del cuento y ayuda a concederle una segunda lectura.

1 De ahora en adelante El ayla.

2 Cabe mencionar, como lo precisa Arguedas (1956: 184) que él «pasó su niñez y adolescencia en Puquio», lo que implica que ya tuvo la oportunidad de ver las celebraciones y danzas ligadas a Limpieza de los acueductos durante ese periodo de su vida. Sobre su estadía en Puquio, ver también Merino de Zela (1970: 128-131). 


\section{LAS CELEBRACIONES DE LA LIMPIEZA DE ACUEDUCTOS: CERTEZAS}

Arguedas (1951: 10) considera que la fiesta comunal celebrada con motivo de la reparación y limpieza de los acueductos comunales «se realiza en toda la sierra peruana». En sus escritos encontramos diferentes denominaciones. Unas veces el nombre es dado sin ser asociado al lugar de su utilización: «Limpieza de los acueductos» (Arguedas \& Duviols, 1975 [1966]: 12), «Limpieza de Acequia» o «Yarqa Aspiy» (1976b [1969]). Otras veces sí los asocia: «Cequia aspiy» (1987a [1941]: 142) en la región del Cusco, «Limpia cequia» en «las provincias castellanizadas del departamento de Lima» ((1987a [1941]: 142), «Huayruna» en la provincia de Huarochirí, también en el departamento de Lima (1951: 10), «Fiesta del Agua» o «Yarqa Aspiy» en Puquio — departamento de Ayacucho— (1954: 180) y «Sequia» o «Fiesta del Agua», también en Puquio (1956: 204 y ss).

Arguedas (1987a [1941]: 143) hace una descripción somera de la limpieza de los acueductos:

«Todos los hombres del ayllu [comunidad indígena] se reúnen en la plaza del pueblo, y bajo la dirección del varayok' [autoridad comunal] van a reparar las tomas de agua y las acequias de regadío, que fueron derrumbadas por los aguaceros y avenidas de los meses de lluvia [...] En muchos ayllus vuelven cantando de esta faena [cequia aspiy]; son cantos especiales y antiguos, con música imperial pura y letra quechua sin mezcla. Cantan todos en gran coro; llegan a la plaza, oscureciendo; allí se encuentran con las mujeres que no toman parte en la faena; se toman de las manos, en parejas, y como una gran cadena, le dan vuelta a la plaza. Cantan hasta muy entrada la noche [... ] después salen a los pampones y a las callecitas del pueblo, pasan corriendo y desde el interior de las chozas los niños escuchan el coro que se aleja y se acerca, con un dulce temor, como si el ruido de las aguas y los arbustos llorara en el pueblo».

En esta larga cita extraída de un artículo considerado «de carácter etnológico» (Fell, 1982: 873) —Arguedas obtendrá su primer título de etnología solamente en 1950 (Fell, 1982: 106)— se puede ver la convicción o la intuición que Arguedas tiene de la antigüedad de los cantos ligados a esta ceremonia. Se ve también, aunque sin ser nombrada como tal, una descripción de la danza ayla que será ampliada después de sus investigaciones en Puquio, como veremos a continuación. Finalmente, y como ha sido constatado (Fell, 1982: 886), Arguedas no se apercibe aún de la gran dimensión religiosa que tiene la Limpieza de los acueductos, de la que tomará conciencia solamente en los años 1950.

En su artículo sobre Puquio, Arguedas (1956: 204) escribe:

«Dos fiestas dedicadas a los Wamanis [dioses Montañas] existen: la Herranza y la "Sequia", es decir fiesta del ganado, y la del agua. En ambas ocasiones se rinde culto a los Wamanis».

En este mismo artículo se encuentran, asociadas a la Fiesta del Agua, casi todas las ceremonias evocadas en el cuento y también la danza ayla, que da nombre al cuento que estudiamos; danza que está siempre asociada a Puquio todas las veces que Arguedas la nombra en sus escritos etnológicos. Siempre en el referido artículo (1956: 226), Arguedas comenta también el carácter prehispánico de esta manifestación religiosa aunque haya signos «católicos en la fiesta», tal como la presencia de cruces. Hemos yuxtapuesto (cuadro 1) los ritos considerados antiguos por Arguedas en 1956 a los ritos evocados en el cuento El ayla, sin incluir las danzas que trataremos luego. 
Cuadro 1 - Ritos considerados antiguos por Arguedas en 1956 y sus evocaciones en el cuento $E l$ ayla

\begin{tabular}{|l|l|l|}
\hline & Arguedas (1956: :...) & El ayla :... \\
\hline El sacrificio de la llama & $206-297$ & 235 \\
Visita a la capilla de piedras y rogatoria al picaflor & $206-207$ & $235-236$ \\
Los altos y adoraciones de los Aukis (sacerdotes & 206 & 236 \\
de la comunidad) en lugares predeterminados & & 236 \\
La recepción a los Aukis & $206,210,212$ & 235 \\
El himno de los Aukis o uh wayli & 212 & 236 \\
La comida ceremonial & 219 & 235 \\
¿Pascua antigua? & & \\
\hline
\end{tabular}

En el cuadro se puede ver que todos los ritos evocados en el cuento El ayla figuran en la publicación de Arguedas de 1956. Lo único que no hemos encontrado es la mención a la «pascua antigua», que en el cuento El ayla parece englobar todas las ceremonias:

«Era la última ceremonia de la pascua antigua con que celebraban la conclusión de la limpieza de los acueductos». (Arguedas, 1956: 234)

Trataremos, más adelante, de explicar a qué pascua se refiere Arguedas. Por el momento, veamos cómo Arguedas presenta los ritos referidos en el cuadro, en sus publicaciones posteriores a esta fecha y anteriores a la aparición del cuento El ayla en 1967.

Arguedas (1976a [1957]: 180-181) cita, como antiguos, casi todos estos ritos y, sobre todo, una parte del himno de los Aukis que es dado como ejemplo de «la poesía quechua oral india más pura» en la que se han incorporado «muchas voces castellanas [...] con extraño acierto, con intuición estética sorprendente». Pero Arguedas (1965: 5) va más lejos aún, ya que utiliza este himno como modelo para estructurar versos de los himnos que nos han dejado algunos cronistas y escribe:

«Intentamos ofrecer un panorama de la poesía quechua desde la época prehispánica hasta el presente. De la época prehispánica hemos elegido cinco himnos religiosos, cuatro recogidos por Santa Cruz Pachacuti y uno por Cristóbal de Molina. La estructura del verso es una arbitraria construcción nuestra. Nos fundamos para hacerlo en el Himno de los aukis de Puquio a los dioses montañas, que grabamos en 1952. Es posible presumir que este himno sea de una antigüedad muy grande».

Se ve, pues, que todas estas alusiones que Arguedas hace a las ceremonias de la limpieza de los acueductos, después de 1956 y hasta 1966 - año de la escritura del cuento, cuyas circunstancias comentaremos más adelante- insisten en la muy probable antigüedad de esas manifestaciones religiosas. ¿Sucede lo propio con las danzas?

\section{LAS DANZAS: AYLA O PIRUCHA O i AYLA Y PIRUCHA?}

Antes de interrogarnos sobre el origen de la danza ayla, creemos necesario hacer un pequeño comentario sobre la confusión existente entre la danza ayla y el pirucha, dada la importancia que tienen para el estudio de nuestro cuento. Arguedas (1956: 222) escribe, refiriéndose al pirucha:

«No nos ha sido posible esclarecer de manera concluyente el significado de esta palabra.

Denomina la danza popular nocturna de la fiesta de la Sequia».

Líneas abajo y después de citar y comentar algunos testimonios, concluye: 
«Designa, pues, más al lugar en que se realiza la danza que a la danza misma, que, sin duda, se denomina ayla».

Georges Pratlong (1985: 62) que asiste a estas celebraciones en los años 1979 y 1980, también en Puquio, considera asimismo que Pirucha es el lugar donde se baila el ayla. Para apuntalar su afirmación este autor cita la conclusión de Arguedas que acabamos de ver, pero Arguedas (1954: 181) escribe, comentando las danzas que tienen lugar también en Puquio durante la Fiesta del Agua, que el pirucha es el baile de los casados y el ayla el de los solteros. Además, Arguedas nos da varios elementos que caracterizan a cada una de ellas, y es posible establecer un cuadro para comparar los principales elementos de las danzas en ambas publicaciones para yuxtaponerlo al cuadro obtenido a partir del cuento El ayla (cuadro 2).

Cuadro 2 - Elementos de la danza ayla y/o pirucha en las publicaciones etnológicas y en el cuento

\begin{tabular}{|c|c|c|c|c|c|c|}
\hline & \multicolumn{2}{|c|}{$\begin{array}{l}\text { Arguedas } \\
(1954: 181)\end{array}$} & \multicolumn{2}{|c|}{ Arguedas $(1956: . .)}$. & \multicolumn{2}{|c|}{ El ayla :.... } \\
\hline (Nombre) & $\begin{array}{l}\text { Ayla: } \\
\text { Solteros }\end{array}$ & $\begin{array}{l}\text { Pirucha: } \\
\text { casados }\end{array}$ & $\begin{array}{l}\text { Pirucha o ayla : } \\
\text { solteros }\end{array}$ & $\begin{array}{l}\text { Pirucha } \\
\text { o ayla: } \\
\text { casados }\end{array}$ & $\begin{array}{l}\text { Ayla : } \\
\text { Solteros }\end{array}$ & $\begin{array}{l}\text { Ayla: } \\
\text { Casados }\end{array}$ \\
\hline Lugar & $\begin{array}{l}\text { Calles y } \\
\text { campos }\end{array}$ & Plazas & $\begin{array}{l}\text { Cruzan de un } \\
\text { barrio a otro. } \\
\text { Campos baldíos } \\
(225)\end{array}$ & $\begin{array}{l}\text { Plazas } \\
(224)\end{array}$ & $\begin{array}{l}\text { Calles, } \\
\text { plaza, } \\
\text { montaña } \\
(236- \\
239)\end{array}$ & $\begin{array}{l}\text { La plaza } \\
(237)\end{array}$ \\
\hline Instrumentos & $\begin{array}{l}\text { Coro de las } \\
\text { mujeres }\end{array}$ & $\begin{array}{l}\text { Arpa y } \\
\text { violín }\end{array}$ & $\begin{array}{llr}\text { Coro } & \text { de } & \text { las } \\
\text { mujeres } & (222 & \text { y } \\
224) & & \end{array}$ & $\begin{array}{l}\text { Arpa y } \\
\text { violín } \quad 0 \\
\text { arpa sola } \\
(224)\end{array}$ & $\begin{array}{l}\text { Coro } \\
\text { mixto } \\
\text { sólo en } \\
\text { la plaza } \\
(237)\end{array}$ & $\begin{array}{l}\text { Arpa } \\
(237)\end{array}$ \\
\hline Coreografía & $\begin{array}{l}\text { En } \\
\text { cadenas, } \\
\text { no se } \\
\text { alternan } \\
\text { por sexos }\end{array}$ & & $\begin{array}{l}\text { En cadenas, las } \\
\text { mujeres atrás, los } \\
\text { hombres adelante } \\
(221-222)\end{array}$ & $\begin{array}{l}\text { Hombres } \\
\text { y mujeres } \\
\text { en círculo } \\
(224)\end{array}$ & $\begin{array}{l}\text { Siempre } \\
\text { en } \\
\text { cadena. } \\
\text { Mujeres } \\
\text { atrás, } \\
\text { hombres } \\
\text { adelante. } \\
\text { (236- } \\
237) \\
\end{array}$ & $\begin{array}{l}\text { Bailan en } \\
\text { círculo } \\
(237)\end{array}$ \\
\hline $\begin{array}{l}\text { Relaciones } \\
\text { sexuales }\end{array}$ & Sugeridas & & $\begin{array}{l}\text { Consideradas } \\
\text { Evidentes y sin } \\
\text { inhibiciones (224- } \\
225)\end{array}$ & & $\begin{array}{l}\text { Descritas } \\
(239)\end{array}$ & \\
\hline
\end{tabular}

El cuadro muestra que, tanto en las publicaciones etnológicas como en el cuento El ayla, los solteros y los casados no bailan la misma danza. Fuera de un lugar común, la plaza, los otros sitios donde se ejecutan, los instrumentos utilizados y la coreografía son diferentes. A ello se añade la posibilidad que poseen solamente los solteros de tener relaciones sexuales; sugeridas o presentadas como casi evidentes en el caso de las publicaciones etnológicas y descritas claramente en el caso del cuento El ayla.

La rápida mención de esta danza en su estudio sobre el Valle del Mantaro (Arguedas, 1953: 241) va también en el mismo sentido: 
«Las más antiguas canciones de indios que he oído en el Sur y Centro se entonan sin acompañamiento de instrumentos: [...] la gran danza de las solteras en la fiesta del agua en algunas provincias de Ayacucho: el Ayla».

Pensamos que esta identificación de la danza ayla al grupo de los solteros podría ser una de las causas por las que Arguedas tratará de encontrar un paralelo con las danzas del Carnaval andino, como veremos luego.

Finalmente, Arguedas (1956: 222) no sólo describe la danza ayla. Respecto a las letras, dice: «la letra del ayla es exclusiva de la fiesta de la "Sequia"» y nos da como ejemplo, en la misma página, una estrofa de las letras del ayla:

$\begin{array}{ll}\text { Terripelo pacha } & \text { Traje de terciopelo } \\ \text { Solterapa churakunan } & \text { traje de soltera } \\ \text { piraq mayraq } & \text { quién, cuál } \\ \text { Churakunqa } & \text { se vestirá con ella, } \\ \text { chay kaqlla } & \text { esa misma } \\ \text { yanay ganqa. } & \text { ha de ser mi amada. } \\ \text { Inschuchallay waylla } & \text { Alta paja mía } \\ \text { Clabelinaschallay. } & \text { mi florecita de clavelina. }\end{array}$

Evidentemente, Arguedas constata que: «La letra del ayla no es alusiva a la fiesta de la "Sequia"; es amatoria». ¿Qué implica en este contexto la escritura del cuento El ayla en 1966? ¿Arguedas encontró el origen de esta fiesta amatoria?

\section{EL CARNAVAL ANDINO O POQOY Y LA «RECONSTRUCCIÓN ETNOHISTÓRICA» DE LA DANZA AYLA}

A partir de los años cuarenta Arguedas se interesa en el Carnaval que se celebra en la sierra peruana y pone de realce su importancia: «El carnaval es la fiesta más grande de los pueblos indios peruanos» (Arguedas, 1987b [1941]: 153) y da un origen probable a esta fiesta:

«No conocemos su verdadero origen. Pero tiene sus danzas propias y su música propia. Y es la más hermosa música de todo el folklore peruano. Debe tener un lejano origen indio puro; porque en el norte, en el centro y en el sur la música de carnaval tiene un genio común [...] La fiesta primitiva, la que hoy se llama carnaval debe ser de origen chanka». (Arguedas, 1987b [1941]: 152-153)

Precisemos que Arguedas sitúa la zona chanka en los departamentos de Huancavelica, Apurímac y Ayacucho, en el sur del Perú (Arguedas, 1958: 142-144).

El interés de Arguedas por conocer el origen de las danzas del carnaval andino toma un nuevo impulso en los años 1960, década en la que traduce el manuscrito de Huarochirí (Arguedas, 1975 [1966]). En su artículo Navidad y Huaylas: de lo mágico a lo nacional, Arguedas (1967: 27) intenta 3 rastrear los orígenes de una danza ligada al carnaval andino y/o a los ritos de la siembra: el huaylas. En esta publicación considera que los antecedentes prehispánicos de esta danza se encuentran en el capítulo 9 del manuscrito de Huarochirí. Afirma también que la danza huaylas y el ayla tienen caracteres comunes: se baila con el coro de las mujeres, es una danza de

3 En la semana de su muerte Arguedas (Arguedas, 1976b [1969]) seguirá insistiendo en su convicción de la antigüedad de varias manifestaciones de la música tradicional peruana y entre ellas del ayla: «La otra gran fuente [habla precedentemente de algunas manifestaciones esculturales] del arte tradicional peruano también se ha salvado: la música. Ahora se imprimen realmente, comprobadamente millares de discos de música indígena y no solamente de la popular sino la de las danzas y ceremonias, matrimonio, haylli, herranza, aylas del Yarqa Aspiy 
solteros y considera, y esto es muy importante, que la danza huaylas «tenía implicaciones erótico religiosas como los carnavales en el valle del Vilcanota o el ayla de Puquio». Pensamos que Arguedas está sugiriendo que el ayla es una danza del carnaval andino. Pensamos también que el cuento El ayla puede confirmar nuestra afirmación. Veamos los juegos eróticos de cazadores y de presas gozosas que se describen en este cuento (1983a [1967]: 238-239) y que tienen lugar en el cerro, durante la noche:

«Las muchachas del ayla empezaron a chillar en ese instante y se dispersaron moviendo los brazos. Dos venían hacia el espino; parecía que volaban bajo. Luego los hombres gritaron con voz gruesa, como la de un gavilán que toma altura precipitadamente. Y se echaron a correr en línea ondulante. Dos mozos persiguieron, cerca del espino, a las muchachas. Ellas reían y chillaban, ellos bufaban, silbaban. Finalmente los hombres lanzaron una especie de zumbido por la boca y las muchachas se quedaron quietas, una a poca distancia de la otra. Cuando los hombres cayeron sobre ellas, se echaron a reír fuerte y a insultar: "Gavilán torcido, gavilán vencido, gavilán tuerto, gavilán ciego, gavilán sin pecho...". Los hombres también gritaban: "Paloma tuerta, paloma sin ojos, paloma sin nada..."”.

Estos juegos eróticos evocan fuertemente los juegos del «Maqta carnaval» (El Carnaval de los jóvenes) de San Pablo — provincia de Canchis, departamento del Cusco- descritos por Arguedas (1966: 65-66):

«Son danzas de solteros, bailes eróticos de iniciación que constituyen un rito propiciatorio de la fecundidad de la tierra. Durante la noche, los jóvenes escalan hasta las cumbres heladas [...] durante el viaje se realizan juegos mágicos: la mujer hará de paloma o venado y el hombre de halcón o de puma y cazará, con goce de su víctima, a la paloma o al venado».

El pueblo de San Pablo, donde tiene lugar este Carnaval, se encuentra situado en el valle del Vilcanota y resulta ser, así, uno de los carnavales que él menciona en la cita que hemos presentado. Podemos, entonces, decir que en el cuento El ayla Arguedas le concede a la danza ayla la ciudadanía carnavalesca andina que no puede concederle en sus escritos etnológicos por falta de pruebas históricas.

Finalmente, en el referido artículo Navidad y huaylas de lo mágico a lo nacional, Arguedas recuerda que, según el capítulo 9 del manuscrito de Huarochirí, la gente del ayllu Surco bailaba el huayllas 4 durante la fiesta del dios Pariacaca. Cabe mencionar que, en dicho capítulo, figuran en sendas notas marginales el nombre y la traducción de la fiesta tanto del dios Pariacaca «Auquisna - / para n(uest)ro padre. o criador» - como la de la diosa Chaupiñamca - «chaycasna - para n(uest)ra m(adr)e» (Taylor, 1999: 128, notas 48 y 49)5. Arguedas no podía ignorar estos nombres y sus traducciones, ya que había traducido el manuscrito. Es más, tiene revueltos en la cabeza estos nombres cuando escribe $E I$ ayla. Recordemos que este cuento forma parte del pequeño conjunto de cuentos Amor Mundo. En una carta del 4.VII. 1966, Arguedas escribe (Fell, 1982: 1137 ):

«Amor Mundo ha crecido. Ya te decía [el destinatario es A...] en mi carta anterior que el primer relato lo escribí como el comienzo de una novela corta. Ella está en marcha. Junto con esta carta recibirás una versión algo corregida del primer relato y el segundo. Tengo comenzado el tercero. Han de ser cinco en total [...] por otra parte debo escribir el estudio para la traducción de un texto quechua del siglo XVI que hice y que he

(Limpieza de Acequia), carnavales, y algunas de estas muestras han de tener hasta milenios de antigüedad y es posible, por no decir seguro, pues no somos especialistas, que no pocas de estas muestras grabadas para la venta comercial se mantuvieran incontaminadamente indígenas durante siglos, tal es el caso del ayla, por ejemplo, del que Raúl García ha logrado hacer en guitarra una interpretación de increíble propiedad».

4 Respetamos esta ortografía del manuscrito de Huarochirí, como lo hace Arguedas en su artículo.

5 No disponemos del texto quechua que Arguedas utilizó para su traducción, pero Taylor ha publicado el suyo y suponemos que es el mismo, por lo cual lo citamos. 
concluido de ordenar para entregarlo a la imprenta».

En el cuento El ayla, los gritos de los hombres al final de los juegos eróticos y antes de la copulación: «yo... yo te voy a hacer empollar, en nombre del Padre, de la Madre» (1983a [1967:] 239), ¿no serían acaso una evocación de los ritos relacionados con Pariacaca y Chaupiñamca? Nosotros pensamos que sí y tenemos un indicio más. En el manuscrito de Huarochirí, tanto Pariacaca, en el capítulo 9, como Chaupiñamca, en el capítulo, 10, dan instrucciones para ser adorados y al conjunto de todas esas adoraciones se le llama «pascua» (Arguedas \& Duviols, 1975 [1966]: 56 y 64 respectivamente). Este término se utiliza también en la versión quechua (pascuakunakta y pascuanta) que presenta Taylor (1999: 122 y 154 respectivamente). Esto podría explicar la alusión que Arguedas hace a la «pascua antigua» en el cuento, alusión que no figura en su publicación Puquio una cultura en proceso de cambio, como lo hemos señalado en el cuadro comparativo (Cuadro 1). Además, la diosa ligada a la limpieza de los acueductos es Chuquisuso (Arguedas \& Duviols, 1975 [1966]: 47-50). La fertilidad está más ligada al dios Pariacaca, ya que quienes no cumplen con las ceremonias que le son dedicadas «se tornan estériles» (Arguedas \& Duviols, 1975 [1966]: 61). La fertilidad está ligada también a la diosa Chaupiñamca:

«Y cuando bailaban y danzaban esta danza [el casayaco, danza erótica que le es dedicada], comenzaba la maduración del mundo» (Arguedas \& Duviols, 1975 [1966]: $64)$.

Cabe recordar que en su tesis, Arguedas (1987c [1963]: 13) señala la superposición del Carnaval católico a las celebraciones del tiempo de la maduración o Poqoy:

«Las fiestas católicas se superpusieron a algunas de las más grandes de la antigüedad peruana (el Corpus Christi al Inti Raymi, el carnaval a las celebraciones del Poqoy, tiempo de la maduración, etc.)».

Así, en el plano ficcional, para la reconstrucción de la danza ayla, Arguedas recurre a los ritos y tradiciones del manuscrito de Huarochirí que traduce y a los datos que recoge y retiene, tanto sobre el Carnaval andino o Poqoy como de la danza ayla. De esta manera, Arguedas transpone al cuento el método de reconstrucción histórica de la etnohistoria:

«La expresión "Etnohistoria" fue forjada por los etnólogos norteamericanos para designar sus tentativas de reconstrucción de la historia de los pueblos indios a partir de tradiciones y de datos acopiados». (Deschamps, 1968: 1433)6

Esta reconstrucción de la danza ayla permite proponer una nueva lectura del cuento $E I$ ayla, como veremos a continuación.

\section{RECONSTRUCCIÓN ETNOHISTÓRICA Y ESTRUCTURA CUENTÍSTICA}

Con la ayuda de los dioses Pariacaca y Chaupiñamca, y utilizando el modelo estructural de los personajes elaborado por Greimas y simplificado por Mélétinski (1987: 197-198), podemos, entonces, establecer un cuadro de la actuación de los personajes desde un punto de vista indio (cuadro 3) en el cuento El ayla.

6 "L'EXPRESSION "Ethno-Histoire" a été forgée par des ethnologues américains pour désigner leurs essais de reconstruction de l'histoire des peuple indiens à partir de traditions et des faits recueillis ». (Deschamps, 1968: 1433) 
Etnohistoria y elaboración literaria en EL Ayla de José María Arguedas

Cuadro 3 - Actuación de los personaje desde el punto de vista indio

\begin{tabular}{|l|l|}
\hline Sujeto & Indias e indios solteros \\
Objeto & Ejecución del ayla, baile de carnaval \\
Remitente & El padre montaña Arayá y la concepción india del amor \\
Destinatarios & Indias e indios solteros \\
Ayudantes & Pariacaca y Chaupiñamca \\
Opositores & Los señores vecinos, el cura, algunos indios \\
\hline
\end{tabular}

Este cuadro muestra la importancia del culto a las montañas o culto wamánico que se extiende casi a lo largo de todo el cuento. El remitente es el padre montaña Arayá y la concepción india del amor. Uno de los participantes dice:

«Por mando del corazón y por mando del gran padre Arayá jugamos; sembramos de noche. Bonito». (1983a [1967]: 237)

El objeto es la ejecución de la danza ayla en la que los solteros, fecundando a sus parejas, «sembrando» (1983a [1967]), participan en la maduración del mundo gracias al principio de magia homeopática que declara que lo semejante produce lo semejante. El sujeto son todos los solteros que han llegado a la edad de la madurez y que tienen pareja. Uno de los participantes dice:

«Yo quizás no voy a ir. No ha llegado mi pareja [...] iAl año entrante sembraré, haré cimiento»! (1983a [1967])

Los destinatarios son también las indias y los indios con pareja. Los opositores son los mestizos y señores que critican esta danza: «Van a hacer sus asquerosidades en el cerro estos indios» (1983a [1967]: 236), por ausencia, los indios que no regresan más de la costa: «De la costa a veces nunca regresa la gente» (1983a [1967]: 237), algunos indios escolarizados que se oponen por desistimiento: «ésos [los que ya saben leer] ya no van, dicen» (1983a [1967]: 236). Los ayudantes son Pariacaca y Chaupiñamca, que establecen, en cierta manera, el modelo arquetipal para luchar contra la esterilidad y favorecer la maduración del mundo. La copulación tendiente a la fecundación se hace en nombre de estas divinidades, es decir en representación de ambas: «yo... yo te voy a hacer empollar, en nombre del Padre, de la Madre» (1983a [1967]: 239). Podemos también incluir entre los ayudantes la actitud, a primera vista contradictoria, de algunos participantes entusiastas de la danza ayla, como la moza Felisa que dice: «El padre Arayá sirve para jugar. No es padre. Es tierrita grande» ${ }^{7}$ (1983a [1967]: 238). Estas palabras no resultan contradictorias si se tiene en cuenta, como ha sido observado en Puquio (Pratlong, 1985: 62), que durante la fiesta de la Sequia o Limpieza de los acueductos ciertas normas sociales son abolidas y que algunas actitudes aparentemente sacrílegas no causan reprobación.

\section{CONCLUSIÓN}

Pensamos que el ostracismo que Arguedas impone a la danza ayla entre 1956 y 1966, tanto en su obra etnológica como en su obra artística, obedece a una búsqueda silenciosa e infructuosa de posibles antecedentes históricos de dicha danza. Con el manuscrito de Huarochirí renacen en Arguedas las esperanzas de resolver este problema, pero no logra hacerlo y opta por otra

7 Para construir esta manifestación de contradicción aparente Arguedas se sirve de sus constataciones. En 1965 escribe (1979: 18) refiriéndose, entre otros, a los indios de Puquio: «Han descubierto que el Wamani o Auki (montaña) es sólo un alto promontorio de tierra y no un poderoso ser de cuya voluntad depende la destrucción o la conservación o aumento de los bienes». 
solución. La danza ayla, en el cuento El ayla, ya no es, para Arguedas, la evocación de la danza típica de la Fiesta del Agua que él describe en sus trabajos etnológicos; es más una danza del Carnaval andino o poqoy. Para su «reconstrucción» e inspirándose en el método utilizado en Etnohistoria, Arguedas recurre a las divinidades de la mitología de Huarochirí y a las danzas de Carnaval del valle del Vilcanota. Esto constituye un magnífico ejemplo del método que Arguedas (12.VI.1960: 8) propone a quienes, pretendiendo teatralizar danzas folklóricas, las despojan de cuanto tienen de original:

«Es que no hay manera de tener éxito en la reconstrucción de las danzas americanas antiguas sobre la bases de los pocos informes de los cronistas. Será siempre necesario recurrir a la fantasía, y entonces el valor de la 'reconstrucción' dependerá por entero del talento artístico de quien lo intente».

Finalmente, Angel Rama (1976: 273) escribe sobre el pensamiento mítico en la obra de José María Arguedas:

«De hecho reencontramos, en el nivel de las formas literarias, la presencia de dos configuraciones culturales distintas que tratan de armonizarse, pero que fluyen paralelamente y fijan dos lecturas simultáneas. La más rica, desde el punto de vista artístico, es la que responde a las operaciones de un pensamiento mítico, aunque ella parecería incapaz de construir por sí sola toda una estructura novelesca, al menos como la entendemos en nuestra tradición occidental».

Consideramos que esta segunda lectura, «que responde a las operaciones de un pensamiento mítico», no es solamente posible en las novelas de Arguedas, o por lo menos en algunas (Calero del Mar, 2001: 328-353). Hemos visto que el cuento El ayla nos ofrece también esta posibilidad.

Agradecimientos

Este artículo se inspira en la conferencia que di en Montréal, en la Universidad Concordia, Department of Classics, Modern Languages and Linguistics, en enero de 2005. Reitero mis agradecimientos, por su invitación, al profesor Antonio Giménez Micó, así como a los otros miembros de su Departamento, por su amable acogida.

\section{A. Referencias citadas}

ARGUEDAS, J. M., 1951 - Incorporación de toro en la cultura indígena. El interesante caso de la conversión del Amaru. Trilce, I, 2- quincena: 3 y 10.

ARGUEDAS, J. M., 1953 - Folklore del valle del Mantaro. Provincias de Jauja y Concepción. Folklore Americano, año I (1): 101-293.

ARGUEDAS, J. M., 1954 - Información bibliográfica. Folklore Americano, año II (2): 175-183.

ARGUEDAS, J. M., 1956 - Puquio, una cultura en proceso de cambio. Revista del Museo Nacional, XXV: 184-232.

ARGUEDAS, J. M., 1958 - Notas elementales sobre el arte popular y religioso y la cultura mestiza de Huamanga. Revista del Museo Nacional, XXVII: 140-194.

ARGUEDAS, J. M., 1960 - «Las danzas Incas del Perú». Una responsabilidad del Ministerio de Educación y de la Universidad. El Comercio, Suplemento Dominical, 12.VI: 8.

ARGUEDAS, J. M., 1965 - Poesía quechua (Selección y presentación por J. M. Arguedas), 95 p.; Buenos Aires: Editorial Universitaria de Buenos Aires. 
ARGUEDAS, J. M., 1966 - Maqta carnaval (Carnaval de los jóvenes). In: Panorama de la música nacional: 65-66; Lima: Casa Mozart (Escuela Nacional de Música y de Danzas Folklóricas).

ARGUEDAS, J. M., 1967 - Navidad y huaylas: de lo mágico a lo nacional. El Comercio, Suplemento Dominical, 22.I: 27.

ARGUEDAS, J. M. \& DUVIOLS, P., 1975 [1966] - Dioses y hombres de Huarochirí, 175 p.; México: Siglo XXI Editores.Traducción castellana de J. M. Arguedas. Estudio bibliográfico de P. Duviols.

ARGUEDAS, J. M., 1976a [1957] - Canciones quechuas. In: José María Arguedas, Señores e indios. Acerca de la cultura quechua: 174-185; Buenos Aires: Calicanto Editorial.

ARGUEDAS, J. M., 1976b [1969] - Salvación del arte popular. In: Señores e indios. Acerca de la cultura quechua: 254-259; Buenos Aires: Calicanto Editorial.

ARGUEDAS, J. M., 1979 [1965] - El indigenismo en el Perú, Latinoamérica. Cuadernos de Cultura Latinoamericana, 55: 5-22.

ARGUEDAS, J. M., 1983a [1967] - El ayla. In: José María Arguedas. Obras completas, t. I: 235239; Lima: Editorial Horizonte.

ARGUEDAS, J. M., 1983b [1967] - Don Antonio. In: José María Arguedas. Obras completas, t. I: 241-238; Lima: Editorial Horizonte.

ARGUEDAS, J. M., 1987a [1941] - El varayok', eje de la vida civil del ayllu. In: José María Arguedas, Indios, mestizos y señores:139-143; Lima: Editorial Horizonte.

ARGUEDAS, J. M., 1987b [1942] - Carnaval de Tambobamba. In: José María Arguedas, Indios, mestizos y señores: 151-155; Lima: Editorial Horizonte.

ARGUEDAS, J. M., 1987c [1963] - Las comunidades de España y del Perú, 343 p.; Madrid: Ediciones Cultura Hispánica.

CALERO DEL MAR, E., 2001 - Le monde préhispanique andin dans la genèse de l'œuvre romanesque de José María Arguedas. Thèse de Doctorat d'Université, Université de Paris $\mathrm{X}, 427 \mathrm{p}$.

DESCHAMPS, H., 1968 - L'Ethno-histoire. In: Ethnologie générale, Encyclopédie de la Pléiade (Jean Poirier, éd.): 1433-1444; Paris, Éditions Gallimard.

FELL, E. M., 1982 - José María Arguedas et la culture nationale dans le Pérou contemporain (1939-1969), 1290 p.; Lille: At. de Reprod. des Thèses.

MÉLÉTINSKI, E., 1987 - El estudio estructural y tipológico del cuento. In: Morfología del cuento (Vladimir Propp, ed.): 179-221, 227-234; Madrid: Editorial Fundamentos.

MERINO DE ZELA, M. E., 1970 - Vida y Obra de José María Arguedas. Revista Peruana de Cultura, 13-14: 127-178.

MURRA, J. V., 1987 - José María Arguedas. Dos imágenes. In: José María Arguedas. Las comunidades de España y del Perú: 7-13; Madrid: Ediciones Cultura Hispánica.

PRATLONG, G., 1985 - La Sequia, Puquio, barrio de Chaupi, août 1979, août 1980. Bulletin de I'Institut Français d'Études Andines, 18 (1): 43-64.

RAMA, A. 1976 - Recuperación del pensamiento mítico en José María Arguedas. Latino-América Anuario. Estudios latino-americanos, 9: 247-274.

TAYLOR, G., 1999 - Ritos y tradiciones de Huarochirí: manuscrito quechua de comienzos del siglo XVII, 502 p.; Lima: Instituto Francés de Estudios Andinos, Banco Central de Reserva del Perú, Universidad Particular Ricardo Palma. 


\section{B. Documentos consultados, pero no citados 8}

ARGUEDAS, J. M., 1959 - Fomentar o dirigir las artes populares. El Comercio. Suplemento dominical, 19. IV: 6-7.

ARGUEDAS, J. M., 1961 - La Soledad Cósmica en la Poesía Quechua. Ideas, Artes y Letras, año XII, 48-49: 1-2

ARGUEDAS, J. M., 1976 [1962] - El monstruoso contrasentido. In: José María Arguedas, Señores e indios. Acerca de la cultura quechua: 215-219; Buenos Aires: Calicanto Editorial.

ARGUEDAS, J. M., 1976 [1962] - Los instrumentos musicales y su área de difusión. «El Jilgurero del Huascarán». In: Señores e indios. Acerca de la cultura quechua: 220-224; Buenos Aires: Calicanto Editorial.

ARGUEDAS, J. M., 1976 [1962] - Los señores y los indios. In: Señores e indios. Acerca de la cultura quechua: 225-232; Buenos Aires: Calicanto Editorial.

ARGUEDAS, J. M., 1976 [1962] - La lira paucina. In: Señores e indios. Acerca de la cultura quechua: 235-238; Buenos Aires: Calicanto Editorial.

ARGUEDAS, J. M., 1965 - Autenticidad contagiosa: danzas de Puno a México. El Comercio, 9. XI: 3.

ARGUEDAS, J. M., 1976 [1965] - Notas sobre el folkore peruano. In: José María Arguedas, Señores e indios. Acerca de la cultura quechua: 209-214; Buenos Aires: Calicanto Editorial

ARGUEDAS, J. M., 1983 - Obras completas, ts. I-V, 282, 236, 352, 488 y 278 pp.; Lima: Editorial Horizonte.

ARGUEDAS, J. M., 1996 - José María Arguedas, recuerdos de una amistad, 309 p.; Lima: Fondo Editorial de la Pontificia Universidad Católica del Perú. Alejandro Ortiz Rescaniere (ed.), presentación y notas de Carmen María Pinilla.

ARGUEDAS, J. M., 1997 - Cartas de José María Arguedas a Pedro Lastra, 151 p.; Santiago de Chile: LOM Ediciones. Edición, prólogo y notas de Edgard O’Hara.

FORGUES, R., 1993 - José María Arguedas. La letra Inmortal. Correspondencia con Manuel Moreno Jimeno, 163 p.; Lima: Ediciones de los ríos profundos.

MURRA, J. V. \& LÓPEZ-BARALT, M., 1996 - Las cartas de Arguedas, 364 p.; Lima: Edición de Fondo Editorial de la Pontificia Universidad Católica del Perú.

8 Basándose nuestro trabajo, en parte, en el silencio de Arguedas sobre la danza ayla, en un periodo de su producción etnológica y artística, nos vemos obligados a presentar, en la sección B, los documentos consultados pero no citados. 